\title{
Cultivating Gratitude: Contemplative Discovery Pathway Theory Applied to Group Therapy in the Bahamas
}

\author{
David F Allen ${ }^{1 *}$, Mallery Mayo ${ }^{1}$, Marie Allen-Carroll ${ }^{1}$, James A Manganello², Victoria S Allen ${ }^{3}$ and Jay P Singh ${ }^{4,5}$
}

${ }^{1}$ Renascence Institute International, Nassau, Bahamas

${ }^{2}$ Private Practice, Lexington, MA, USA

${ }^{3}$ College of the Bahamas, Nassau, Bahamas

${ }^{4}$ Molde University College, Molde, Norway

${ }^{5} \mathrm{Global}$ Institute of Forensic Research, Reston, VA, USA

\begin{abstract}
The positive psychology movement has given us new ways to conceptualize behavior. However, little research has been conducted examining the benefits of promoting the development of positive characteristics such as gratitude and love as part of treatment. To address this gap, the present article describes the implementation of a group therapy program grounded in Contemplative Discovery Pathway Theory (CDPT). The innovative program, "The Family", focuses on the discovery process to resocialize a sample of community members from the Bahamas. We conclude with a case vignette and recommendations for future research directions.
\end{abstract}

Keywords: Gratitude; Contemplative discovery pathway theory; Group therapy; Forgiveness

\section{Introduction}

For generations, four positive emotional experiences have influenced the thoughts and writings of philosophers and theologians: gratitude, forgiveness, humility, and love. Research in the field of health psychology shows that these emotional experiences are key ingredients to healthy interpersonal relationships and can reduce an individual's risk of internalizing psychiatric disorders such as depression and externalizing disorders such as substance abuse [1-3].

Gratitude refers to a community-focused emotion that can be defined as an awareness of all that is good in the world coupled with a belief that this goodness comes from an external source [4]. Increasingly, descriptive research is establishing gratitude as being strongly associated with both physical as well as psychological wellbeing [5-7]. Although gratitude has been said to be "one of the few things that can measurably change people's lives" [4] the effect of promoting gratitude as part of psychosocial interventions has received comparatively little attention.

Also linked with well-being is forgiveness, which refers to the emotional and cognitive experience of restoring a social relationship following a transgression [8]. Related to forgiveness are the character strengths of humility, which is the placing one's needs second to those of another [9], and love, which is the ability to build strong attachments to others in which both parties feel understood and valued $[10,11]$.

These three supplementary emotions have been found to relieve individuals from weighted feelings of shame [12]. Shame by its very nature is persistent and its effects insidious, lingering long after a hurtful thought or event has passed or been forgiven. Indeed, factor analytic research conducted as early as the 1970s has demonstrated that shame is among the strongest precipitants of adverse psychiatric outcomes [13]. And in the wake of the tragic school shooting in Newtown, Connecticut, in the United States, a more fervent call has been issued to identify treatment approaches that may assist "withdrawn and isolated" and "angry and alienated" individuals diagnosed with a mental illness who may be experiencing extreme feelings of shame [14].

It may be that therapeutic interventions focusing on overcoming shame and promoting the positive emotional experiences of gratitude, forgiveness, humility, and love represent a promising way forward. However, such interventions have not been described or tested in practice settings. Hence, the aim of the present paper is to put forth a comprehensive theory and therapeutic approach that may aid in the process of resocialization (i.e., the process of discovering an inner vision of the Self extending beyond one's limitations to experience one's potential) and diminish feelings of shame through the cultivation of gratitude, forgiveness, humility, and love.

\section{Contemplative Discovery Pathway Theory}

Contemplative Discovery Pathway Theory (CDPT) was developed as an alternative to cognitive-behavioral theory that motivates clients beyond recovery to a stage of discovery, which focuses on universal ethical principles involving justice, equality, and respect for all humans. A developmental model, CDPT postulates that the Self follows a stepwise path from the Natural Self at birth to the Shame Self and its antithesis, the Shame False Self, in early development to the healthier Authentic Gracious self in adulthood and potentially even the Contemplative Transcendent Self late in life. In the following sections, we describe each of these stages in greater detail.

\section{The Natural Self at Birth}

Following the Judeo-Christian tradition, an individual comes from love, is born to love, and upon death returns to love. According to the CDPT, an infant's instinctual need for unconditional love at birth may be conceptualized as being comprised of three dimensions: Survival/ Security, Affection/Esteem, and Power/Control. These dimensions represent powerful sources of energy that interact with one another

*Corresponding author: David F Allen, Renascence Institute International, \#207 Lagoon Court, Sandyport, Nassau, Bahamas, USA, Tel: 242-327-8719; Fax: 242327-8718; E-mail: dfallen43@gmail.com

Received May 19, 2014; Accepted June 26, 2014; Published June 28, 2014

Citation: Allen DF, Mayo M, Carroll MA, Manganello JA, Allen VS, et al. (2014) Cultivating Gratitude: Contemplative Discovery Pathway Theory Applied to Group Therapy in the Bahamas. J Trauma Treat 3: 197. doi:10.4172/2167-1222.1000197

Copyright: ( 2014 Allen DF, et al. This is an open-access article distributed under the terms of the Creative Commons Attribution License, which permits unrestricted use, distribution, and reproduction in any medium, provided the original author and source are credited. 
as the child struggles to establish basic trust [15]. A child exposed to a meaningful environment of stability, consistency, and predictability will undergo a separation individuation from the primary caretaker (often the mother, though not necessarily so) to form his or her identity as one who trusts his- or herself [16]. The internalization of the primary caretaker (the nurturing object) provides for the development of self-object transference within the child. As described by Kohut [17], self-objects are relationships that maintain the cohesion, vitality, strength, and harmony of the Self. These relationships form the basis for the development of human community. They also open one to the experience of shame.

\section{The shame self and false shame self}

As an individual develops, he or she faces life challenges and inevitable failures as well as successes. Having experienced a lack of unconditional love from other humans, individuals experience hurt, woundedness, and deprivation in one or more of the instinctual needs. From the perspective of CDPT, when persistent trauma and pain occurs early in life, all domains of instinctual need are affected through the development of a Shame Self, characterized by a number of shame schemata (Table 1). The emotional experiences associated with this Shame Self are so painful to confront directly that the mind creates a Shame False Self as a defense mechanism. This Shame False Self is addictive in nature and characterized by self-absorption, selfgratification, and a need for control. In reality, however, the Shame False Self is an obstacle to personal development.

\section{The Authentic Gracious Self}

By becoming aware of the Shame False Self through selfdevelopment, therapy, and/or spiritual guidance opens the door to the creation of an Authentic Gracious Self. It is critical to develop insight to the Shame False Self in order to be able to consciously embrace oneself wholly. During CDPT therapy, the client becomes aware of and confronts his or her shame, opening his or her heart to the experience of unconditional love. Thus, the person is able to discover a vision of the Authentic Gracious Self characterized by the appreciation of solitude, community, compassion, humility, and gratitude. The Authentic Gracious Self is not a fixed goal, but rather an ideal that one must continually and consciously seek to continue benefiting from the accompanying senses of relaxation, creativity, proactivity, and openness to the challenge and joy of living.

\section{The Contemplative Transcendent Self}

Many who have experienced the Authentic Gracious Self are awestruck at the experience of transcendence, a sense of oneness with the universe. Such experiences may occur through therapy, religion, nature, or the unconditionally kind acts of other humans. Paradoxically, the experience may also occur in response to a tragedy or illness which can result in people seeking out a power greater than themselves. Within the context of CDPT, such transcendence is viewed as a gift resulting from deep commitment and faithfulness. In our experience, the Contemplative Transcendent Self requires spiritual discipline to develop, including practices such as mindful prayer, solitude, and sacred reading. The deeper love manifested in the Contemplative Transcendent Self represents the death of the Shame Self, resulting in a deep sense of joy that absorbs chaos, exudes calm, and instills hope.

\section{Principles of Treatment}

CDPT embraces seven fundamental principles of treatment which will be described below: (1) therapy as a whole person process, (2) the development of insight, (3) experiencing vulnerability and developing empathy, (4) addressing cognitive components of shame, (5) authenticity, (6) humor, and (7) contemplative prayer.

\section{Therapy as a whole person process}

Therapy is an ongoing process designed to address different aspects of a client's life including his or her shame. Working through shame creates space for the awareness and experience of love. By focusing on transforming the whole individual rather than simply reinforcing individual behaviors, a more comprehensive set of physical and social changes may result.

\section{The development of insight}

Therapy from the standpoint of the CDPT model is like physical therapy. Just as when a muscle has a knot it needs to be massaged over and over again until the knot or cramp disappears, so the healing of the mind requires repeated massage and working through for healing to be effective. Thus, insights from treatment need to be revisited and developed skills practiced to be useful in the long-term.

\section{Experiencing vulnerability and developing empathy}

Working through thoughts and feelings of shame both exposes and increases vulnerability. Vulnerability is not weakness but rather willingness to accept the uncertainty, risk, and emotional exposure of daily life. Such acceptance is a result of the client's courage, purpose, and commitment to face reality. The level of defensiveness that stands in the way of vulnerability reflects the client's fear, disconnection,

\begin{tabular}{|l|l|l|l|}
\hline & Shame Schemata & \multicolumn{2}{l|}{} \\
\hline Manifestation & Abandonment & Rejection & Humiliation \\
\hline Anger & Not aware & Fraid of anger & Vindictive cold anger \\
\hline Boundaries & Few or impenetrable (may switch) & Materialistic comparison & Rigid \\
\hline Consumer Needs & Materialistic reductionism & Controllable & Controlling \\
\hline Control & May manipulate by controlling or allowing self to be & Unstable & Decisive \\
\hline Decision-making & Indecisive & Co-dependency & Contra-dependency \\
\hline Dependency & Either co- or contra-dependent & Variable self esteem, make comparison to others & Low/High self-esteem, competitive \\
\hline Esteem & Low self-esteem, feeling of inadequacy & Copes with fear by pleasing others \\
\hline Fear & Paralyzed by fear & Passive aggressive \\
\hline Frustration & Manipulative & Connects to prevent isolation \\
\hline Isolation & Isolated & Controlled by feelings & Defends against fear with bravado \\
\hline Motivations & Confused between feelings and thoughts & Moderate & Connects for selfish interests \\
\hline Self-absorption & Extreme & Controlled by thoughts & Extreme \\
\hline
\end{tabular}

Table 1: Shame schemata and manifestations. 
and shame. Once vulnerability can be experienced by oneself, the vulnerabilities of others may be experienced through the development of empathy. Empathy combats shame and enables the client to feel valued and respected by being better able to value and respect others.

\section{Addressing cognitive components of shame}

One sees the world and others through the lens of his or her thoughts. Shameful thoughts are cynical, gloomy, and generally negative. The experience of the shame of failure may produce negative thoughts that create a vicious cycle of self-fulfilling prophecies, increasing the likelihood of failure, poor self-image, and alienation. Clients are instructed that shameful thoughts and labels encourage such self-sabotage and that focusing on the self is a hallmark of the Shame False Self reflected when an individual over-personalizes events and experiences. In addition, clients are warned of the negative consequences of blaming others, which can create a passive victim mentality that makes constructive change more difficult.

\section{Authenticity}

To let go of the expectations and consciously embrace oneself is important in the CDPT model. Operationally, such authenticity involves not only sharing one's life story but also owning that story no matter how painful the events therein. As a client becomes more authentic, shame decreases.

\section{Humor}

The ability to laugh at oneself is a powerful antidote to shame. It is a self-transcendent experience and provides the client with a sense of mastery. In its expression, one experiences a form of surrender. The client realizes that his or her essential being cannot be characterized only by shame.

\section{Contemplative prayer}

Spirituality reflects a relationship with a higher power grounded in compassionate love. True spirituality includes expressions of awe, reverence, peace, joy, meaning, value, purpose, hope, humility, and gratitude. Therapy associated with spiritual development incorporates contemplative practices (e.g., personal accountability, silence, prayer, mindfulness, sacred reading, community, and the doing of good deeds). This process leads to the formation of the Contemplative Transcendent Self and can help to move a client from recovery to a discovery mindset.

\section{The Role of the Therapist}

Shame is difficult to treat because it is ubiquitous, evasive, deeply internalized, and hidden. Compared to other emotions able to be released by catharsis and grief, shame is difficult to admit, express, and discharge. Shame can also be difficult to identify, as it has few associated verbal and non-verbal expressions with the exception of blushing, the turning away of the body, downcast eyes, and a muted voice [18]. Hence, the identification of shame can require a keen alertness on the part of the therapist to be able to pick up the subtle signs.

Developing a meaningful therapeutic alliance with a client in CDPT therapy requires patience, understanding and compassion. As the client re-experiences shameful thoughts and events, the therapist may become a disavowed object of hate, rejection, and disgust. In concordance with the psychoanalytic conceptualization of transference, the therapist must accept the negative introject in a loving manner with self-containment, respect, and a non-judgmental attitude. The therapist's work with transference takes special skill and assumes that he or she has already dealt with and accepted his or her own shame through a therapeutic intervention. If not, some therapistclient relationships may end up reinforcing the False Shame Self and impeding the development of the Authentic Gracious Self.

\section{Shifting from Shame to Love}

The concept of shifting from shame to love is introduced in therapy as a way to change a client's perception of the world by working through his or her shame. Focusing on love instead of fear is a counterinstinctual choice for the client, requiring conscious effort to overcome the illusion of the False Shame Self. As Sir John Templeton observed, "Unfortunately, too often people focus on the negatives and lose sight of the multitude of blessings that surround us and the limitless potential that exists for the future" [19]. Central to facilitating the shift from shame to love is teaching clients the 10 principles of "Conscious Shifting" (see Appendix).

\section{Implementation of "THE FAMILY"}

CDPT's developmental emphasis and goal of promoting selfdiscovery of the Contemplative Transcendent Self through empathy and contemplative prayer provided the foundation for a unique group therapy approach in the Bahamas: The Family. The Family was started in 2009 to improve socialization and confront the prevailing community adversity currently experienced in the Bahamas. The motto of The Family is "Jaw, jaw stops war, war." That is, if members of the community can dialogue, the resultant socialization creates a suitable environment for the teaching and cultivation of virtues such as gratitude, forgiveness, humility, and love. In theory, the group creates a therapeutic replica of a family, allowing clients to confront their issues in a safe and non-judgmental environment. Like other countries in the world, the Bahamas has suffered from a devastating cocaine epidemic starting in the 1980s and continuing to the present. The drug crisis along with recent socio-economic troubles has led to a powerful dissocialization and erosion of socio-cultural values.

The Family provides support and advocacy for its members, allowing them to discover themselves and grow as individuals. Albeit a faith-based intervention, clients are given the opportunity to practice the spiritual aspects of the approach in any way they choose. At any given point in time, clients in the group will include between 40 and 50 mostly Bahamian adults, including referrals from the community or courts due to delinquent behavior, domestic violence, substance abuse, grief, vengefulness, anger management, conflict resolution, and traumatization from crime [20].

\section{Group process}

Family groups meet for two hours weekly, moderated by a therapist with the assistance of a co-therapist. Sessions are open, and new participants are welcome to join at any time. No fee is charged and therapists volunteer all services. Each group meets in a room where the chairs are arranged in a large circle so that members can see one another. Sessions begin with each member of the group introducing himself or herself and sharing the reason for being there and what they expect. Participation is optional, with discussions being guided by the therapists. At the end of each session, a therapist provides a summary of the group and offers a psychological/spiritual teaching to foster education and character development.

A few basic rules are in place to govern and maintain the confidentiality of the group. First, each person admitted to the group is given an individual intake session to identify their issues and expectations from the group. Second, during group sessions, members are encouraged to offer insight and opinions to other members of the 
group without being judgmental. Third, participants are encouraged to be punctual, supportive and to share openly. Fourth, persons suffering from a mental illness must be in compliance with their medications, and their doctor or medical clinic must be informed that they are attending the program. Fifth, as everything shared in the group is confidential, members may only share information about themselves with non-group members. Sixth and finally, special attention is made when discussing painful topics such as rape, incest, sexual abuse, or catastrophic loss.

\section{Illustrative Case}

Anecdotal reports from group members frequently reflect positive outcomes after participating in The Family. The case described below serves as an exemplar, illustrating an average therapeutic process from the perspective of CDPT. Identifying information has been changed out of respect for client confidentiality.

A 40-year-old, separated mother of three children was referred for services by her attorney. The attorney felt she was in crisis and was at high risk of either suicide or homicide. She claimed her life between the ages of 9 and 17 years was traumatic, as she had been sexually abused by her father. She reported marrying her husband to get out of her home environment; however, her husband was unfaithful, frequently abusing her. When the client was first interviewed, she was depressed and spent much of her time in contact with police and the courts.

She was initially overwhelmed by a negative self-image, necessitating individual therapy to uncover feelings of shame associated with being abused by her father and husband. In these sessions the client expressed deep feelings of anger towards men, often expressed as negative transference with her male therapist. She was subsequently referred to The Family to continue working on uncovering her feelings of shame.

The first sessions as part of The Family were difficult for the client, though she did receive positive feedback from other group members. She demonstrated signs of her Shame Self through anger, selfabsorption, and overeating. Initially, the insight that her Shame False Self increased her pain and accentuated her low self-esteem resulted in more hopelessness and suicidal ideation. However, as she continued to attend The Family, she began to show more vulnerability and began to empathize with the pain of other group members. Her increased ability to connect with members of the group helped her to better visualize her Authentic Gracious Self and, in turn, she began expressing gratitude for her situation. The gratitude she felt also reflected alignment with her Contemplative Transcendent Self. At this point, she stated that she knew only God-a figure larger than herself-could have saved her. After attending the group for 3 years, she re-married and continues to actively work to maintain her Authentic Gracious Self. Given such positive anecdotal evidence, it is our intention to begin empirically studying the efficacy of The Family in promoting positive outcomes.

\section{Future Directions}

At the individual, group, and societal levels, applying CDPT can lead to a discovery of a Gracious Authentic Self as well as a Transcendent Self through the cultivation of gratitude, forgiveness, humility, and love. Combating shame in a manner that provides lasting, positive change for clients, the CDPT model emphasizes selfdiscovery from a cognitive-spiritual perspective. The next step will be to qualitatively and then quantitatively test the model in a longitudinal fashion using assessment and outcome data collected over the past five years. Preliminary qualitative analyses suggest that participation in The
Family have shown an improvement in depressive symptomatology as well as a greater capacity for interpersonal intimacy and trust. As part of continued longitudinal study of the efficacy of this intervention, we plan on developing a statistically-reliable assessment instrument to effectively measure resocialization at the level of the individual. Baseline scores on this assessment instrument will be retrospectively derived for when they first entered treatment. Adjusting for the length of time spent in The Family, we plan on examining changes in gratitude, forgiveness, humility, and love using non-parametric statistical methods such as dependent samples t-tests. Finally, additional Family groups will be established in the coming year under the auspices of newly trained counsellors both in the Bahamas as well as in the United States, which we hope will provide insight on the impact of culture on the effectiveness of the therapeutic model.

\section{References}

1. Kendler KS, Liu XQ, Gardner CO, McCullough ME, Larson D, et al. (2003) Dimensions of religiosity and their elationship to lifetime psychiatric and substance use disorders. Am J Psychiatry 160: 496-503.

2. Tsang J, McCullough M E, Fincham FD (2006) The longitudinal association between forgiveness and relationship closeness and commitment. Journal of Social and Clinical Psychology 25: 448-472.

3. Westberg G (2010) Good grief - 50th anniversary edition. Augsburg Fortress Publishers, Minneapolis.

4. Emmons R (2007) Thanks!: How practicing gratitude can make you happier. Houghton Mifflin, Boston.

5. Emmons R (2004) The psychology of gratitude: An introduction, The psychology of gratitude, Oxford University Press, New York.

6. Emmons RA, McCullough ME (2003) Counting blessings versus burdens: an experimental investigation of gratitude and subjective well-being in daily life. $J$ PersSocPsychol 84: 377-389.

7. Gordon AM, Impett EA, Kogan A, Oveis C, Keltner D (2012) To have and to hold: gratitude promotes relationship maintenance in intimate bonds. J PersSocPsychol 103: 257-274.

8. Bono G, McCullough ME, Root LM (2008) Forgiveness, feeling connected to others, and well-being: two longitudinal studies. PersSocPsychol Bull 34: 182195.

9. Powers C, Nam R, Rowatt WC, Hill P (2007) Associations between humility spiritual transcendence, and forgiveness. Brill Academic Publishers, Herndon, VA.

10. Allport S (1997) A natural history of parenting. Harmony Books, New York

11. Meyers DG (1999) Close relationships and quality of life. Well-being: The foundations of hedonic psychology. New York: Russell Sage Foundation.

12. Allen DF (2010) Shame: The human nemesis. Eleuthera Publications, Washington.

13. Izard CE (1972) Patterns of emotions: A new analysis of anxiety and depression San Diego: Academic Press.

14. Walkup JT, Rubin DH (2013) Social withdrawal and violence--Newtown, Connecticut. N Engl J Med 368: 399-401.

15. Erikson EH (1993) Childhood and society. Norton and Co, New York.

16. Mahler M, Pine F, Bergman A (1974) The psychological birth of the human infant: Symbiosis and individuation. Basic Books, New York.

17. Kohut H (1984) How does analysis cure? Chicago: University of Chicago Press

18. Vick SJ, Waller BM, Parr LA, Smith Pasqualini MC, Bard KA (2007) A Crossspecies Comparison of Facial Morphology and Movement in Humans and Chimpanzees Using the Facial Action Coding System (FACS). J Nonverbal Behav 31: 1-20.

19. Herrmann RL (2004) Sir John Templeton: Supporting scientific research for spiritual discoveries. West Conshohocken, Templeton Foundation Press, PA.

20. Westberg G (2010) Good grief - 50th anniversary edition. Augsburg Fortress Publishers, Minneapolis. 


\section{Appendix}

1. Awareness that we can shift from shame to love: Although love is always present in the world, you can live without awareness of that love. It is a choice to live in shame, and doing so puts you in a victim mentality. Consciously acknowledging love is a first step in self-transformation, as the willingness to empty the heart of shame opens you to love.

2. Stopping to take time out: Shame, fear and anger speed us up by way of physiological arousal, resulting in emotional and physical fatigue. Alternatively, experiencing love slows us down, resulting in emotional and physical recovery. Hence, taking time out for a break, even a brief one, can result in clearer judgment and decision-making.

3. Confronting shame directly: An awareness and re-experiencing of the hurt experienced over time allows for the identification of shame triggers. Working through these triggers can reduce their negative effects. To confront shame directly, you can actively write down the experiences and emotions associated with past shameful experiences. It may also be helpful to develop a timeline of shame (pinpointing ages and events to discuss in the therapeutic context).

4. Deep breathing with eyes closed: Breathing is synonymous with life. When we were young and carefree we breathed deeply. Age and the worries of life lead us to shallow breathing, which can lead to anxiety and increased irritability. Closing your eyes while breathing deeply allows you to relax further, and taking time to focus on relaxing individual body parts can result in even deeper relaxation.

5. Silence: Remaining silent for a few minutes will allow your own heart rate to settle and make you more aware of your deeper self. Focus on the universal love in the greater world around you.

6. Prayer: With your mind relaxed, admit your problems and ask your God or the universe around you to open your heart to love. Whereas human love is temporal and temperamental, eternal love is unchanging and unconditional. However, we frequently lose sight of eternal love and focus on seeking the love of those around us. A simple prayer or meditation can help you to focus on anchoring yourself in eternal love. Your prayer might be, "God have mercy upon me and forgive my resistance to your love. I surrender my heart and shame to your healing and unfailing love."

7. Identify streams of love: Most of us can identify a person in our childhood who expressed unconditional love toward us. Perhaps it was a parent, relative, pastor, priest, rabbi, teacher, or even a stranger. Who provided a stream of love to you? Think of or write down the names of those persons and, as you do this, you will begin to relax and shift from focusing on shame to love. 
8. Identify a sacred space of love: In a sacred space we feel free, loved, and inspired. For many of us from the Bahamas, the sea provides that place. Visiting a sacred space - either physically or mentally - is relaxing and provides another way to shift from focusing on shame to love. Although we may only physically visit a sacred place one time, the memory and sense of personal meaning it brought us can feed us for years to come. Try to reexperience all of the sensations associated with that space when you imagine yourself there.

9. Gratitude: Being thankful for what is often taken for granted is a doorway to love and enables us to move beyond shame to self-transcendence and new meaning. Practicing such gratitude allows you to experience your deepest self. To facilitate a shift to gratitude, write down three things for which you are grateful.

10. Practicing love: After shifting from shame to love, practice love by reaching out to others. Make a commitment to view the world through a lens of love. Practice seeing without thinking, naming, judging, or interpreting - just be present. Whether those around you are expressing love in return or appealing for love through anger or fear, respond lovingly. Seek not only recovery but also discovery of your Contemplative Transcendent Self. 